\title{
Wing-size heritability in a natural population of Drosophila subobscura
}

\author{
DORCAS J UANA ORENGO* \& ANTONIO PREVOSTI \\ Departament de Genètica, Facultat de Biologia, Universitat de Barcelona, Avda. Diagonal, 645, 08071 Barcelona, \\ Spain
}

\begin{abstract}
Heritability of wing size was determined in a natural population of Drosophila subobscura for two consecutive year samples. In the 1988 sample, heritability in the laboratory environment was around $15 \%$, whereas the lower bound in nature was around $0.1 \%$. On the other hand, in the 1989 sample, heritability in the laboratory was around $90 \%$ and in nature around $15 \%$. Differences between the two years could be caused by the more variable climate in which the males used as fathers of the 1988 sample developed. This indicates the importance of determining the environment in which parents developed in nature before discussing the heritability values obtained.
\end{abstract}

Keywords: Drosophila subobscura, heritability, natural populations, wing size.

\section{Introduction}

Body size in Drosophila seems to be moulded by the action of natural selection. Its adaptive nature is suggested by the observation that this character varies regularly with temperature: larger flies appear in cooler environments, whereas smaller flies appear in warmer environments. Latitudinal clines have been described in several species (Prevosti, 1955a; Misra \& Reeve, 1964; Pfriem, 1983; Coyne \& Beecham, 1987; James et al., 1995; Pegueroles et al., 1995) as well as altitudinal clines (Stalker \& Carson, 1948; Prevosti, 1961) and cyclical seasonal changes (Stalker \& Carson, 1949; Prevosti, 1955b). In addition, a rapid evolutionary divergence in body size has been observed in flies reared at different temperatures in the laboratory (Anderson, 1973; Partridge et al., 1994).

On the other hand, body size in Drosophila is related to several fitness components such as mating success (Monclús \& Prevosti, 1971; Santos et al., 1988; Taylor \& Kekic, 1988), fecundity (Robertson, 1957; Tantawy \& Vetukhiv, 1960; Santos et al., 1992) or longevity (Tantawy \& Vetukhiv, 1960; Santos et al., 1992).

Natural selection, the essential process by which populations adapt to the environment, requires three conditions: (i) phenotypical variation;

*Correspondence.

E-mail: dorcas@porthos.bio.ub.es differential fitness; and (iii) heritability. Body size is a character that clearly complies with the first two conditions. In addition, high values of heritability have been reported in the laboratory (Roff \& Mousseau, 1987). Nevertheless, it should be borne in mind that body size is a polygenic character that is easily influenced by environmental conditions (food and temperature) during development (McFarquhar \& Robertson, 1963; David et al., 1983). Heritability is defined as the ratio of additive genetic variance to phenotypic variance: $h^{2}=V_{\mathrm{A}} / V_{\mathrm{P}}$. So, as heterogeneity is expected to be higher in nature, phenotypic variance in nature would also be expected to be higher than in the laboratory (showing the plasticity of the traits) and, consequently, heritability to be much lower a priori. So, in order to understand the importance of body size response to natural selection, its heritability in the wild must be determined. Estimation of the heritability in nature is difficult because it is necessary to know the family relationships among individuals, which is impossible in natural populations of Drosophila. Nevertheless, an indirect method has been developed. Riska et al. (1989) showed that a lower bound on heritability in nature can be obtained from the regression of offspring raised in the laboratory on parents raised in the natural environment, provided that an estimate of additive genetic variance in the laboratory is known. In addition, using this method, it is possible to obtain both laboratory and field estimates of 
heritability for the same trait and population that permit comparisons between them.

Weigensberg \& Roff (1996) analysed heritability estimates obtained from 45 studies reported in the literature, and they found that, for morphological traits, there were no significant differences between laboratory and field estimates. However, only eight studies provided estimates of heritability for both environments for the same trait and population. In these cases, laboratory heritability tended to be higher than field estimates, but the differences were not significant, and there was a high correlation between them. These authors, therefore, concluded that laboratory estimates of heritability should generally provide reasonable estimates of both the magnitude and the significance of heritability in nature. Nevertheless, Coyne \& Beecham (1987) and Simons \& Roff (1994) found that heritability was lower in the field.

Drosophila subobscura is probably the European species of Drosophila most widely used in studies of natural population genetics. Body size in this species shows a latitudinal cline of genetic origin (Prevosti, 1955a; Misra \& Reeve, 1964; Pfriem, 1983; Pegueroles et al., 1995), which suggests the action of natural selection on this character. A parallel latitudinal cline for body size has also been detected in $D$. obscura, a closely related sympatric species (Pegueroles et al., 1995). Therefore, these clines are likely to be adaptive (Endler, 1986). Before it can be stated that body size is subject to natural selection, it must be shown to have a heritability greater than zero in nature. Nevertheless, to our knowledge, no study on the heritability of this character in nature has been performed for D. subobscura. The purpose of this study is to analyse the phenotypic variation of body size in a natural population of $D$. subobscura and calculate a lower bound of its heritability in nature (Riska et al., 1989) for two consecutive year samples.

\section{Materials and methods}

\section{Characters}

Wing length and wing width were used as indicators of adult body size. Wing length was measured along longitudinal vein IV as the sum of two partial lengths, L1 (from the base of the fourth longitudinal vein to the posterior cross vein) and L2 (from the posterior cross vein to the tip of the fourth longitudinal vein) (Prevosti, 1955a). Wing width was measured from the tip of the fifth vein to the costal border running perpendicular to the fourth vein. Measurements were made with a Zeiss microscope with an ocular micrometer inserted into a $10 \times$ ocular lens in combination with a $3.2 \times$ objective. One micrometer unit equals $0.03 \mathrm{~mm}$.

\section{Natural population}

Two samples of D. subobscura were caught in the Fabra observatory fields (Barcelona, Spain) at the beginning of the autumn population explosion. This site is near Barcelona, and exhaustive climatic records are available. The vegetation is typical of the area: a sparse pine forest with some ilexes and Mediterranean brushwood. Flies were netted over bait consisting of fermenting bananas. Body size was measured in 419 males from a collection made in November 1988 and in 629 males from another collection made in November 1989.

\section{Heritability estimation}

A 100-male sample was taken randomly from each collection. Each male was mated individually to two randomly selected virgin females from a laboratory strain derived from a previous collection at the same site (in 1989, the correlation between the two parents was $r=0.075, P=0.286$, for length and $r=-0.017, P=0.805$, for width). When larvae were visible in the cultures, each female was transferred to a new culture bottle to separate their offspring, and the male was preserved in alcohol-glycerine $(2: 1 \mathrm{v} / \mathrm{v})$. Cultures were kept in a walk-in chamber maintained at $17.5^{\circ} \mathrm{C}, 75 \%$ humidity and constant light. The offspring of each female were preserved in alcohol-glycerine. Later, three males were chosen at random from the offspring of each female, and their wings were measured (so six sons from each wild male were measured).

This experimental design gave us the opportunity to obtain both laboratory and field estimates of heritability for the same population. The heritability in the laboratory was calculated from a half-sibs analysis (Falconer, 1981). The 'natural heritability' $\left(h_{\mathrm{N}}^{2}\right)$ was calculated according to Riska et al. (1989). These authors worked with regressions of offspring on midparent, and their formula was adapted to our experimental design of offspring on a single parent:

$4 b_{\left(\mathrm{O}_{\mathrm{L}} \cdot \mathrm{P}_{\mathrm{N}}\right)}^{2}\left(\frac{V_{\mathrm{PN}}}{V_{\mathrm{AL}}}\right)=r^{2} h_{\mathrm{N}}^{2} \leq h_{\mathrm{N}}^{2}$,

where $b$ is the slope of the regression of laboratoryreared offspring $\left(\mathrm{O}_{\mathrm{L}}\right)$ on fathers caught in the wild $\left(\mathrm{P}_{\mathrm{N}}\right), V_{\mathrm{PN}}$ is the phenotypic variance in nature, $V_{\mathrm{AL}}$ is the additive genetic variance in the laboratory and $r$ 
is the additive genetic correlation between the trait in nature and the same trait in the laboratory. The value of $r^{2}$ is unknown unless covariances among relatives in nature are available but, by definition, it must be between 0 and 1 . So, setting $r^{2}=1$ in $r^{2} h_{\mathrm{N}}^{2}$ gives us a lower bound of $h_{\mathrm{N}}^{2}$.

To obtain $b_{\left(\mathrm{O}_{\mathrm{L}} \cdot \mathrm{P}_{\mathrm{N}}\right)}$, covariance analysis was performed by dividing the data set into two groups, such that offspring of the two females mated to each male were put into separate groups. No differences between the two groups were found in any case (two characters and two years), and the common regression coefficient was used as $b_{\left(\mathrm{O}_{\mathrm{L}} \cdot \mathrm{P}_{\mathrm{N}}\right)}$.

\section{Results}

Wing length and width distributions tend to be leptokurtic and skewed to the left, as shown in Fig. 1 for wing length. This situation is similar to that observed for several morphometric characters in several Drosophila species (McFarquhar \& Robert- son, 1963; Santos et al., 1992). This type of distribution does not allow a simple transformation of data to a normal distribution. Thus, although data were tested for statistical significance by using conventional parametric statistics, nonparametric statistics were also carried out and, in all cases, the same conclusions were reached.

Table 1 shows that males caught in the wild in 1988 were smaller than those caught in 1989 $(P<0.001)$. The males used as fathers in the heritability experiment were chosen randomly, as confirmed by the fact that they did not present significant differences from the global wild sample. The males reared in the laboratory were larger than their wild-caught fathers in the 1988 sample (statistically significant for wing length, $P<0.05$, and almost significant for wing width, $0.05<P<0.1$ ), whereas they were slightly smaller in the 1989 sample.

Phenotypical variance in the laboratory-reared flies $\left(V_{\mathrm{PL}}\right)$ was smaller than in the wild-caught flies $\left(V_{\mathrm{PN}}\right)$ (Table 2), as reported by other authors
1988 Wild-caught males

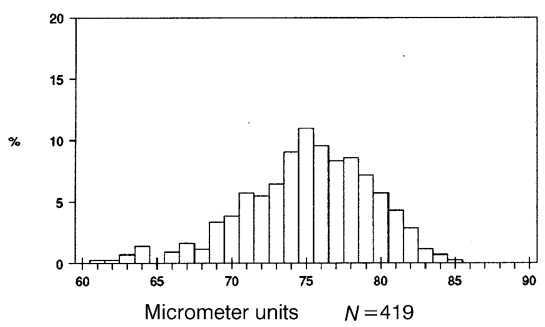

1988 Wild-caught fathers

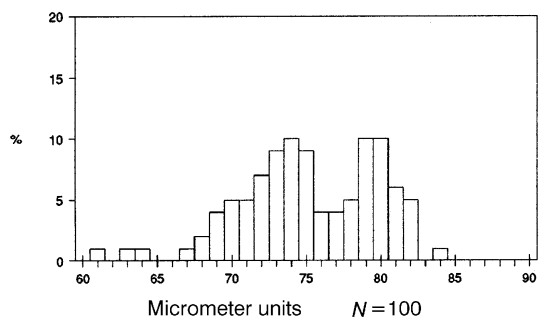

1988 Laboratory-reared sons

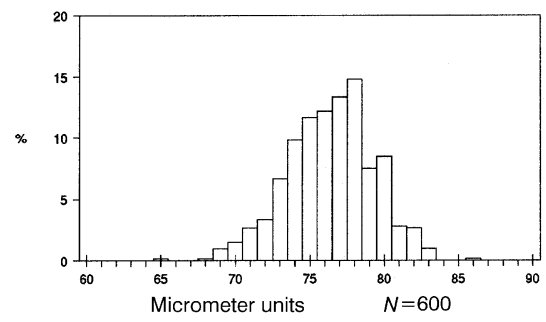

1989 Wild-caught males

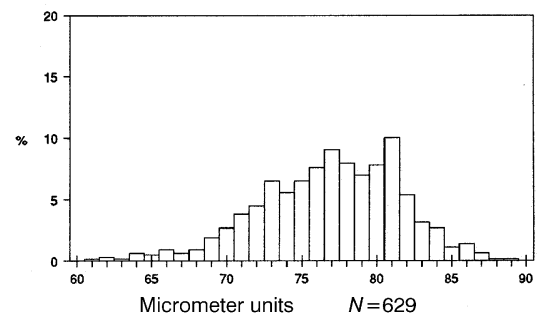

1989 Wild-caught fathers

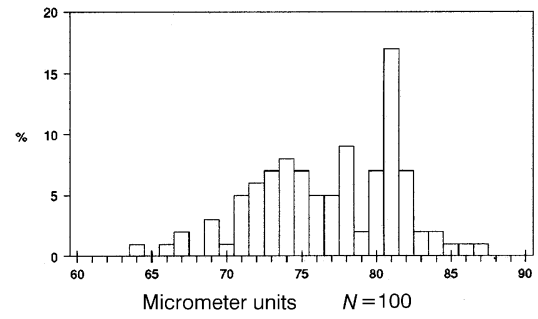

1989 Laboratory-reared sons

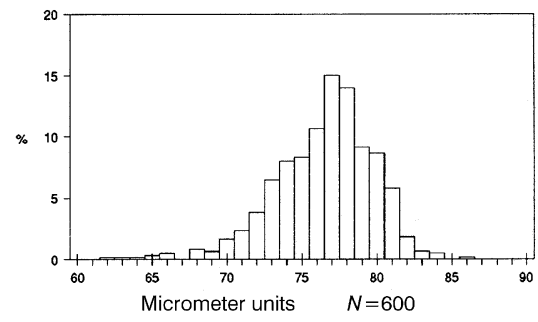

Fig. 1 Wing length distributions of wild-caught male Drosophila subobscura, wild-caught fathers and laboratory-reared offspring for the two years.

(c) The Genetical Society of Great Britain, Heredity, 82, 100-106. 
(McFarquhar \& Robertson, 1963; Coyne \& Beecham, 1987; Santos et al., 1988; Prout \& Barker, 1989).

Table 2 also shows the estimates of the three different heritabilities calculated. Taking these values together, three main trends can be seen. First, no differences between heritability for wing length and wing width were observable. Secondly, the values obtained for the 1988 sample were always lower than those obtained for the 1989 sample. And thirdly, heritability in the laboratory $\left(h_{\mathrm{L}}^{2}\right)$ was greater than the lower bound of the heritability in nature $\left(r^{2} h_{\mathrm{N}}^{2}\right)$, and heritability across both environments $\left(h_{\mathrm{LN}}^{2}\right)$ had a value between the other two.

The values of $h_{\mathrm{L}}^{2}$ calculated for the 1988 sample (Table 2) were around 15\%, and those obtained for the 1989 sample were higher, around $90 \%$. It should be borne in mind that heritability estimates tend not to be precise (Falconer, 1981), as in this case in which the standard errors were very high. Nevertheless, differences between the two years were signifi-

Table 1 Wing length and wing width in wild-caught male Drosophila subobscura and their laboratory-reared offspring

\begin{tabular}{|c|c|c|c|}
\hline & $n$ & $\begin{array}{l}\text { Wing length } \\
\text { Mean } \pm \text { SE }\end{array}$ & $\begin{array}{l}\text { Wing width } \\
\text { Mean } \pm \text { SE }\end{array}$ \\
\hline \multicolumn{4}{|l|}{1988} \\
\hline$\hat{s} \widehat{s}$ nature & 419 & $75.12 \pm 0.21$ & $33.47 \pm 0.10$ \\
\hline Fathers & 100 & $75.20 \pm 0.46$ & $33.43 \pm 0.21$ \\
\hline Sons & 600 & $76.50 \pm 0.15$ & $33.90 \pm 0.13$ \\
\hline \multicolumn{4}{|l|}{1989} \\
\hline ônature & 629 & $76.90 \pm 0.19$ & $34.08 \pm 0.09$ \\
\hline Fathers & 100 & $76.84 \pm 0.47$ & $34.17 \pm 0.21$ \\
\hline Sons & 600 & $76.48 \pm 0.33$ & $33.80 \pm 0.14$ \\
\hline
\end{tabular}

Values in micrometer units. cant, as a $t$-test demonstrates $(P<0.001)$. The additive coefficient of variation $\left(C V_{\mathrm{A}}\right)$ was also compared between the two years, because Houle (1992) argues for the use of this statistic rather than heritability for comparative purposes. In 1988, the values of $C V_{\mathrm{A}}$ in the laboratory were $1.33 \pm 0.04$ and $1.50 \pm 0.04$ for wing length and wing width, respectively, whereas in 1989 , they were $4.17 \pm 0.12$ and $4.02 \pm 0.12$. So, differences between the two years were significant $(P<0.001)$.

Regression of the phenotypic value of laboratoryreared offspring against their wild-caught fathers gives an estimation of heritability across both environments, $h_{\mathrm{LN}}^{2}=2 b_{\left(\mathrm{O}_{\mathrm{L}} \cdot \mathrm{P}_{\mathrm{N}}\right)}$. This value also increased from nonsignificant values, lower than $1 \%$ or even a negative value, in 1988, to statistically significant values $(P<0.05)$, around 25\%, in 1989 (Table 2). Differences between the two years were tested by means of covariance analyses, which revealed significant differences for both wing measures $(P<0.05)$.

Finally, the lower bound of heritability in nature (Table 2) for both length and width of wing is negligible in 1988, whereas in 1989 it shows values of $18 \%$ for length and $13 \%$ for width, which are important in the highly variable natural environment. It should be borne in mind that the values could be greater, because these are only lower bounds.

\section{Discussion}

Wing size is determined by genetic and environmental factors. In the laboratory, environmental factors may be controlled to some extent. Thus, although differences between the wing sizes of the two wild samples might be caused by genetic and/or environmental factors, differences between the two offspring samples must be mainly caused by genetic

Table 2 Variances and heritabilities of wing size in Drosophila subobscura

\begin{tabular}{lrrrrrr}
\hline Trait & $V_{\mathrm{PN}}$ & $V_{\mathrm{PL}}$ & $V_{\mathrm{AL}}$ & $h_{\mathrm{L}}^{2}$ & $h_{\mathrm{LN}}^{2}$ & $r^{2} h_{\mathrm{N}}^{2}$ \\
\hline 1988 & & & & & & \\
Wing length & 20.94 & 8.59 & 1.03 & $12.03 \pm 15.0$ & $0.7 \pm 7.7$ & 0.10 \\
Wing width & 4.45 & 1.72 & 0.26 & $15.23 \pm 15.4$ & $-2.8 \pm 7.3$ & -1.33 \\
1989 & & & & & & \\
Wing length & 22.17 & 11.02 & 10.16 & $92.22 \pm 23.7$ & $29.3 \pm 9.3$ & 18.69 \\
Wing width & 4.54 & 2.10 & 1.85 & $88.22 \pm 23.3$ & $23.1 \pm 8.9$ & 13.08 \\
\hline
\end{tabular}

$V_{\mathrm{PN}}$, phenotypic variance in nature; $V_{\mathrm{PL}}$, phenotypic variance in the laboratory; $V_{\mathrm{AL}}$, additive genetic variance in the laboratory; $h_{\mathrm{L}}^{2}$, heritability in the laboratory estimated as four times the intraclass correlation of half-sibs; $h_{\mathrm{LN}}^{2}$, heritability across both environments estimated as twice the regression of laboratory-reared offspring against fathers from nature; $r^{2} h_{\mathrm{N}}^{2}$, lower bound of heritability in nature. 
factors. Wild-caught males in 1988 were smaller than those caught in $1989(P<0.001)$, but the wing sizes of their offspring, raised in the laboratory, were not significantly different. The average environmental temperature recorded for the 2 months before collection (the period in which most individuals are expected to have developed) was $19.09^{\circ} \mathrm{C}$ in 1988 and $18.46^{\circ} \mathrm{C}$ in 1989 (Fabra observatory records). Thus, size variations between the two samples show the same trend as those observed when rearing Drosophila at different temperatures (David et al., 1983). Taken together, these data suggest that differences between the two samples from the wild are mainly caused by environmental factors.

Phenotypic variance was lower in the laboratory than in nature. This decrease in variance might be because of the more stable and homogeneous environmental conditions in the laboratory. Thus, this may indicate a reduction in the environmental phenotypic variance relative to additive genetic variance, which would result in higher heritability in the laboratory than in nature (Falconer, 1981; Coyne \& Beecham, 1987; Riska et al., 1989).

Heritability across both environments $\left(h_{\mathrm{LN}}^{2}\right)$ increased from nonsignificant values in 1988 to significant values $(P<0.05)$ in 1989 (Table 2). Phenotypic variance in nature was similar for the two years, and the offspring of both samples were reared under basically the same conditions, very homogeneous within each annual sample. Nevertheless, the 1989 sample showed higher additive variance. Thus, differences in heritability across environments between the two samples indicate that the phenotypic variance of the wild-caught males in 1988 has a greater residual variance than in 1989. This could be because these flies developed in a more heterogeneous environment. Although D. subobscura can use very different substrata to develop (Shorrocks, 1982), little is known about their use of the natural resources. Thus, it is possible to analyse only the physical differences in the environment in which the two samples probably developed. Among physical environmental factors, temperature during development has an important effect on adult size (David $e t$ $a l ., 1983)$. Both oscillations and range of variation in daily average temperature during the 2 months before collection were higher in 1988 than in 1989 (Fig. 2). The range of variation was $12.8^{\circ} \mathrm{C}$ in 1988 , whereas it was $8.3^{\circ} \mathrm{C}$ in 1989 . This is important because Drosophila populations contain overlapping generations; at any time, the adult flies of a population have developed at different periods. The

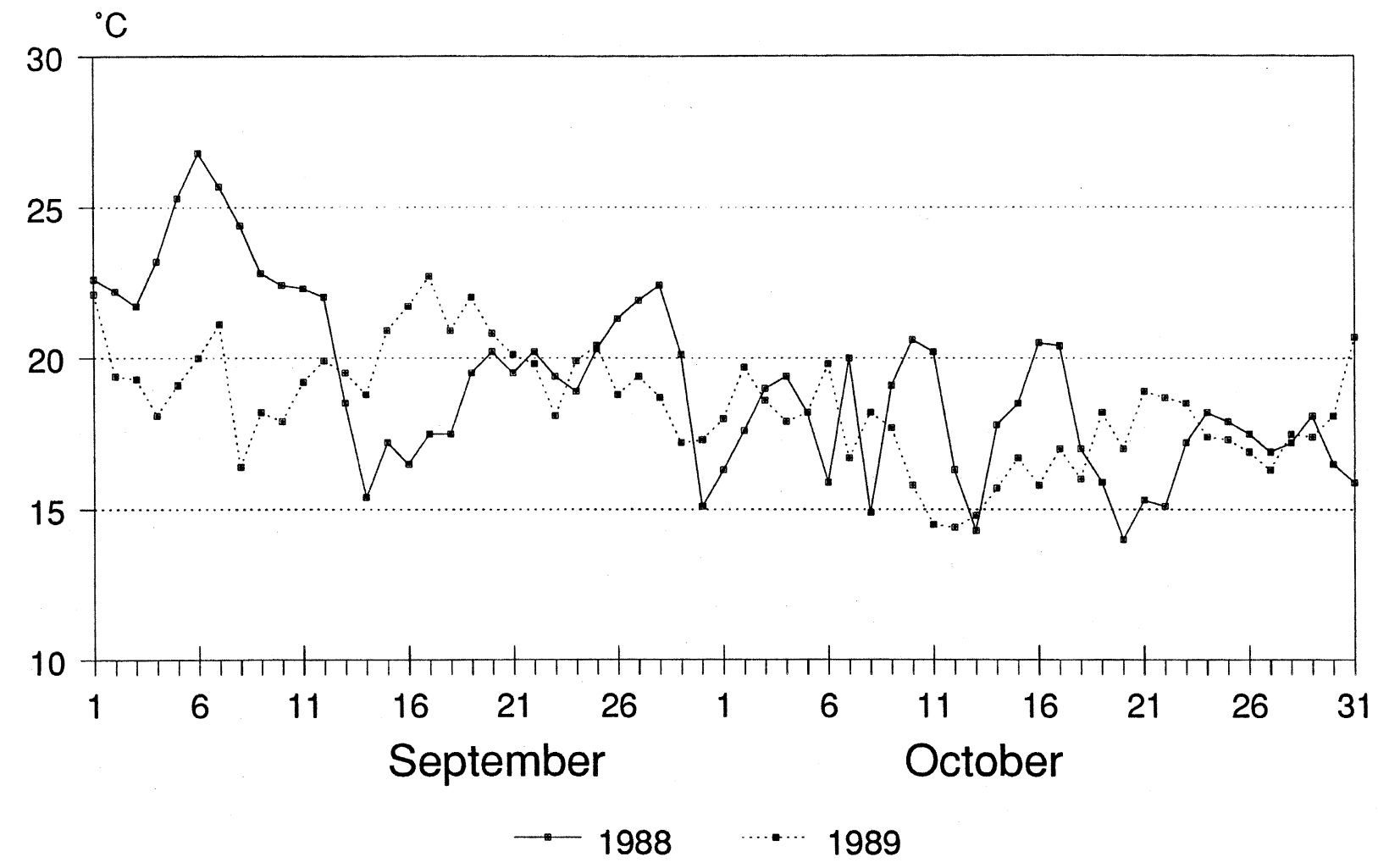

Fig. 2 Daily average temperature during the 2 months before collections.

(C) The Genetical Society of Great Britain, Heredity, 82, 100-106. 
greater range of variation in temperature in 1988 would make phenotypic variance reflect the phenotypic plasticity of this character in response to environment, rather than its genetic variation. This is expressed as a lower heritability across both environments.

Quality or quantity of available food must be important body size-determining factors, but both may be influenced by temperature. In addition, temperature by itself must be a very important determining factor. Simons \& Roff (1994) studied heritability in 'constant' and 'variable' environments. Full-sib individuals of the same families were used in both environments and were fed identically. The 'constant' environment was growth chambers with controlled photoperiod and constant temperature, and the 'variable' environment was cages under field light and temperature conditions. They found a substantial reduction in $h^{2}$ in the more variable environment.

Studies on the heritability of Drosophila in nature are very sparse. Prout \& Barker (1989) reported an appreciable thorax length heritability for $D$. buzzatii, although they found high variations when considering subsamples coming from different individual rotting cactus cladodes. In D. melanogaster, Coyne \& Beecham (1987) found that wing length is significantly heritable when wild-reared flies are used as parents. Nevertheless, in a similar experiment, Prout (1958) found a negative correlation for wing length between wild-caught fathers and their laboratoryraised offspring, suggesting a natural heritability of body size of zero. All these differences in heritability estimates in nature reported by different authors or for different subsamples agree with our results, which show great differences between the two annual samples. This reinforces the fact that heritability depends on a large number of genetic and environmental factors. Heritability is not a specific or populational characteristic, and its estimation is only valid for the population and circumstances in which it is calculated. It is clear from our study that it is very important to determine the environmental conditions in which wild-caught individuals have developed, in order to discuss the heritability values calculated in nature. More stable environmental conditions increase the heritability, whereas more variable conditions reduce the heritability value for the same character (Falconer, 1981).

The estimated values of the heritability in nature for the 1988 sample do not permit any conclusion to be drawn, because they only provide a lower bound. On the other hand, the values estimated for the 1989 sample indicate that body size in Drosophila subobscura may be regulated by the action of natural selection, as has already been suggested by the latitudinal clines described in the literature (Prevosti, 1955a; Misra \& Reeve, 1964; Pfriem, 1983; Pegueroles et al., 1995).

\section{Acknow ledgements}

We wish to thank the Real Academia de Ciencias y Artes de Barcelona and especially Mr Gàzquez for allowing access to the Fabra observatory climatic records.

\section{References}

ANDERSON, w. w. 1973. Genetic divergence in body size among experimental populations of Drosophila pseudoobscura kept at different temperatures. Evolution, 27, 278-284.

COYNE, J. A. AND BEECHAM, E. 1987. Heritability of two morphological characters within and among natural populations of Drosophila melanogaster. Genetics, 117, 727-737.

DAVID, J. R., ALLEMAND, R., VAN HERREWEGE, J. AND COHET, Y. 1983. Ecophysiology: abiotic factors. In: Ashburner, M., Carson, H. L. and Thompson, J. N. Jr, (eds) The Genetics and Biology of Drosophila, vol. 3d, pp. 105-170. Academic Press, London.

ENDLer, J. A. 1986. Natural Selection in the Wild. Princeton University Press, Princeton, NJ.

FALCONER, D. S. 1981. Introduction to Quantitative Genetics, 2nd edn. Longman, Harlow.

HOUle, D. 1992. Comparing evolvability and variability of quantitative traits. Genetics, 130, 195-204.

JAMES, A. C., AZEVEDO, R. B. R. AND PARTRIDGE, L. 1995. Cellular basis and developmental timing in a size cline of Drosophila melanogaster. Genetics, 140, 659-666.

McFARQUHAR, A. AND ROBERTSON, F. W. 1963. The lack of evidence for co-adaptation in crosses between geographical races of Drosophila subobscura Coll. Genet. Res., 4, 104-131.

MISRA, R. K. AND REEVE, E. C. 1964. Clines in body dimensions in populations of Drosophila subobscura. Genet. Res., 5, 240-256.

MONCLÚS, M. AND PREVOSTI, A. 1971. The relationship between mating speed and wing length in Drosophila subobscura. Evolution, 25, 214-217.

PARTRIDGE, L., BARRIE, B., FOWLER, K. AND FRENCH, V. 1994. Evolution and development of body size and cell size in Drosophila melanogaster in response to temperature. Evolution, 48, 1269-1276.

PEGUERoles, G., PAPACEIT, M., QUiNTANA, A., GUILlÉN, A., PREVOSTI, A. AND SERRA, L. 1995. An experimental study of evolution in progress: clines for quantitative traits in colonizing and Palearctic populations of Drosophila. Evol. Ecol., 9, 453-465. 
PFRIEM, P. 1983. Latitudinal variation in wing size in Drosophila subobscura and its dependence on polygenes of chromosome O. Genetica, 61, 221-232.

PREVOSTI, A. 1955a. Variación geográfica de caracteres cuantitativos en poblaciones británicas de Drosophila subobscura. Genética Ibérica, 7, 3-44.

PREVOSTI, A. 1955b. Variación estacional en las dimensiones del ala de Drosophila subobscura. Genética Ibérica, 7, 45-54.

PREVOSTI, A. 1961. Variación con la altitud en caracteres cuantitativos de Drosophila subobscura. Bol. R. Soc. Esp. Hist. Nat. (B), 59, 29-34.

PROUT, т. 1958. A possible difference in genetic variance between wild and laboratory population. Drosoph. Inf. Serv., 32, 148-149.

PROUT, T. AND BARKER, J. S. F. 1989. Ecological aspects of the heritability of body size in Drosophila buzzatii. Genetics, 123, 803-813.

RISKA, B., PROUT, T. AND TURELli, M. 1989. Laboratory estimates of heritabilities and genetic correlations in nature. Genetics, 123, 865-871.

ROBERTSON, F. W. 1957. Studies in quantitative inheritance. XI. Genetic and environmental correlation between body size and egg production in Drosophila melanogaster. J. Genet., 55, 428-443.

ROFF, D. A. AND MOUSSEAU, T. A. 1987. Quantitative genetics and fitness: lessons from Drosophila. Heredity, 58, $103-118$

SANTOS, M., RUIZ, A., BARBADILLA, A., QUEZADA-DÍAZ, J. E., HASSON, E. AND FONTDEVILA, A. 1988. The evolutionary history of Drosophila buzzatii. XIV. Larger flies mate more often in nature. Heredity, 61, 255-262.

SANTOS, M., RUIZ, A., QUEZADA-DÍAZ, J. E., BARBADILla, A. AND FONTDEVILA, A. 1992. The evolutionary history of Drosophila buzzatii. XX. Positive phenotypic covariance between field adult fitness components and body size. $J$. Evol. Biol., 5, 403-422.

SHORROCKS, в. 1982. The breeding sites of temperate woodland Drosophila. In: Ashburner, M., Carson, H. L. and Thompson, J. N. Jr (eds) The Genetics and Biology of Drosophila, vol. 3b, pp. 385-428. Academic Press, London.

SIMONS, A. M. AND ROFF, D. A. 1994. The effect of environmental variability on the heritabilities of traits of a field cricket. Evolution, 48, 1637-1649.

STALKER, H. D. AND CARSON, H. L. 1948. An altitudinal transect of Drosophila robusta Sturtevant. Evolution, 2, 295-305.

STALKER, H. D. AND CARSON, H. L. 1949. Seasonal variation in the morphology of Drosophila robusta Sturtevant. Evolution, 3, 330-343.

TANTAWY, A. O. AND VETUKHIV, M. o. 1960. Effects of size on fecundity, longevity and viability in populations of Drosophila pseudoobscura. Am. Nat., 94, 395-403.

TAYLOR, C. E. AND KEKIC, v. 1988. Sexual selection in a natural population of Drosophila melanogaster. Evolution, 42, 197-199.

WEIGENSBERG, I. AND ROFF, D. A. 1996. Natural heritabilities: can they be reliably estimated in the laboratory? Evolution, 50, 2149-2157. 